\title{
First report of Curvularia leaf spot caused by Curvularia muehlenbeckiae on Zizania latifolia in China
}

\author{
Xijun Chen ${ }^{1,2} \cdot$ Tao Tang $^{1} \cdot$ Chen Chen ${ }^{1,2} \cdot$ Lihui Wei $^{3} \cdot$ Dongmei Zhou $^{3}$
}

Received: 16 November 2020 / Accepted: 3 June 2021 / Published online: 15 June 2021

(c) Società Italiana di Patologia Vegetale (S.I.Pa.V.) 2021

Keywords Zizania latifolia $\cdot$ Curvularia muehlenbeckiae $\cdot$ Leaf spots · New host

Zizania latifolia, a perennial aquatic vegetable, has a long history of cultivation in China (Guo et al. 2007). A leaf spot, observed on Z. latifolia with $70 \%$ incidence in fields of Jiangsu Province in July 2018, caused a 20\%-30\% loss of production. Initial disease symptoms were small brown flecks on the adaxial side of leaf, which later developed into brown spots $(0.2-0.5 \times 0.8-1.5 \mathrm{~cm})$ with an ashen center and a brown extension line along the leaf veins. When the spot coverage rate exceeded $90 \%$, the infected plant died. ZLC1 strain was isolated from an infected leaf sterilized with $2 \%$ chloros by single-spore isolation. The colony, composed of septahyphae, was dark gray on PDA and its diameter reached $7.92 \pm 0.08 \mathrm{~cm}$ in 6 days. Conidia were ellipsoidal, tri-septate, smooth, 9.75-14.01 × 18.39-25.93 $\mu \mathrm{m}$, and dissymmetrically curved at the third cell from the base. Conidiophores were geniculate, septate, brown, and smooth. Molecular identification was performed by analysis of the ITS, GAPDH and EFl $\alpha$ sequences (Tan et al. 2014). The nucleotide sequences of ZLC1 (GenBank accession Nos. MW928429, MZ157282, MZ073340) had a very high identity exceeding $99.13 \%$ with the sequences of Curvularia muehlenbeckiae isolates from Muehlenbeckia from India (HG799002, LT715806) and Saccharum officinarum from China (MN263973). Phylogenetic analysis confirmed the identification as $C$. muehlenbeckiae. Pathogenicity tests were performed twice by spraying a spore suspension $\left(10^{6}\right.$ spores $\left./ \mathrm{mL}\right)$ on 10 prickled leaves of $Z$.

Xijun Chen

xjchen@yzu.edu.cn

1 Horticulture and Plant Protection College, Yangzhou University, Yangzhou 225009, China

2 Joint International Research Laboratory of Agriculture and Agri-Product Safety of Ministry of Education of China, Yangzhou University, Jiangsu, Yangzhou 225009, China

3 Institute of Plant Protection, Jiangsu Academy of Agricultural Science, Nanjing 210014, China latifolia with three replicates in vitro. At room temperature and $90 \% \mathrm{RH}$, lesions developed on the 4th day, and all the inoculated leaves were severely infected after 7 days (Online Resources 1). All the re-isolated cultures identified by morphology were from C. muehlenbeckiae. Previously, C. muehlenbeckiae has been reported as a pathogen of Cunninghamia lanceolate (Cui et al. 2020). To our knowledge, this is the first report of C. muehlenbeckiae on Z. latifolia.

Supplementary Information The online version contains supplementary material available at https://doi.org/10.1007/s42161-021-00880-8.

Funding This work was partially supported by China Agriculture Research System (Funding No. CARS-24-C-01) and Science and Technology Project of Jiangsu Province (Funding No. BE2018359).

\section{Declarations}

Conflict of interest The authors declare no conflict of interest.

\section{References}

Cui WL, Lu XQ, Bian JY, Qi XL, Li DW, Huang L (2020) Curvularia spicifera and Curvularia muehlenbeckiae causing leaf blight on Cunninghamia lanceolate. Plant Pathol 69(6):1139-1147

Guo HB, Li SM, Peng J, Ke WD (2007) Zizania latifolia Turcz. cultivated in China. Genet Resour Crop Ev 54(6):1211-1217

Tan YP, Madrid H, Crous PW, Shivas RG (2014) Johnalcornia gen. et. comb. nov. and nine new combinations in Curvularia based on molecular phylogenetic analysis. Australas Plant Path 43(6):589-603

Publisher's note Springer Nature remains neutral with regard to jurisdictional claims in published maps and institutional affiliations. 